\title{
Relaxation therapy and continuous ambulatory blood pressure in mild hypertension: a controlled study
}

\author{
G A van Montfrans, J M Karemaker, W Wieling, A J Dunning
}

\begin{abstract}
Objective-To determine the long term effects of relaxation therapy on 24 hour ambulatory intraarterial blood pressure in patients with mild untreated and uncomplicated hypertension.

Design-Four week screening period followed by randomisation to receive either relaxation therapy or non-specific counselling for one year. Ambulatory intra-arterial blood pressure was measured before
\end{abstract} and after treatment.

Setting-Outpatient clinic in Amsterdam's university hospital.

Subjects -35 Subjects aged 20-60 who were being treated by general practitioners for hypertension but were referred to take part in the study. At three consecutive screening visits all subjects had a diastolic blood pressure without treatment of 95 $110 \mathrm{~mm} \mathrm{Hg}$. Subjects were excluded if they had damaged target organs, secondary hypertension, diabetes mellitus, a cholesterol concentration $>8 \mathrm{mmol} / \mathrm{l}$, or a history of malignant hypertension.

Interventions - The group allocated to relaxation therapy was trained for eight weeks (one hour a week) in muscle relaxation, yoga exercises, and stress management and continued exercising twice daily for one year with monthly visits to the clinic. The control group had the same attendance schedule but had no training and were requested just to sit and relax twice a day. All subjects were asked not to change their diet or physical activity.

Main outcome measure-Changes in ambulatory intra-arterial blood pressure after one year of relaxation therapy or non-specific counselling.

Results-Mean urinary sodium excretion, serum concentration of cholesterol, and body weight did not change in either group. Diastolic pressures measured by sphygmomanometry were 2 and $3 \mathrm{~mm} \mathrm{Hg}$ lower in subjects in the relaxation group and control group respectively at the one year follow up compared with initial readings. The mean diastolic ambulatory intra-arterial pressure during the daytime had not changed after one year in either group, but small treatment effects could not be excluded: the mean change for the relaxation group was $-1 \mathrm{~mm} \mathrm{Hg}$ ( $95 \%$ confidence interval -6 to $3.9 \mathrm{~mm} \mathrm{Hg}$ ) and for the control group $-0.4 \mathrm{~mm} \mathrm{Hg}(-5.3$ to $4.6 \mathrm{~mm} \mathrm{Hg})$. Mean ambulatory pressure in the evening also had not changed over the year, and in both groups nighttime pressure was $5 \mathrm{~mm} \mathrm{Hg}$ higher. The variability in blood pressure was the same at both measurements.

Conclusions-Relaxation therapy was an ineffective method of lowering 24 hour blood pressure, being no more beneficial than non-specific advice, support, and reassurance-themselves ineffective as a treatment for hypertension.

\section{Introduction}

Behavioural techniques for treating mild hypertension have generated much interest and debate. Not surprisingly, official statements are cautious about the usefulness of arousal-reduction treatments ${ }^{12}$ as even in well conducted studies the results are equivocal.
Several methodological problems in determining the effect of these treatments have been identified, ${ }^{3}$ the most important being whether these strategies produce a genuine persistent fall in blood pressure rather than a brief fall that is a conditioned response to the presence of the therapist. ${ }^{+}$Conversely, true effects might be underestimated if assessments are based on only readings obtained in the clinic. The assessment of the specific effects of arousal-reduction treatments is also controversial: placebo treatments can substantially reduce blood pressure, and appropriate controls for arousal-reduction studies are notoriously difficult to achieve. ${ }^{35}$

We conducted a randomised trial to address both these issues. We studied the effect on blood pressure over 24 hours of a comprehensive arousal-reduction programme including yoga exercises and muscle relaxation $^{6}$ and the programme's specificity by comparing it with non-specific counselling, a convincing placebo approach known to have no effect on blood pressure.

\section{Patients and methods}

\section{SELECTION OF PATIENTS}

We estimated that 25 subjects were needed in each group to permit detection of clinically important differences $(>5 \mathrm{~mm} \mathrm{Hg})$ in ambulatory diastolic blood pressure during the day between the groups with $80 \%$ power $(\mathrm{p}<0.05)$, assuming a standard deviation of $7 \mathrm{~mm} \mathrm{Hg}$. We invited all general practitioners in the Amsterdam region to refer patients aged 20-60 with mild uncomplicated hypertension to the study. Patients with documented damaged target organs, secondary hypertension, or diabetes mellitus were excluded. Each patient's blood pressure was measured by sphygmomanometry at three consecutive clinic visits one week apart (screening period). Only those who were not receiving drug treatment and had a systolic blood pressure between 160 and $200 \mathrm{~mm} \mathrm{Hg}$ or a diastolic pressure between 95 and $110 \mathrm{~mm} \mathrm{Hg}$, or both, at each of these visits were included in the study. Patients receiving hypertensive drugs were taken off treatment and the first screening measurement was taken one week later.

During the year in which patients could join the study 116 were referred. Of these, 53 did not have hypertension and five had blood pressures above the entry limits. Four others were excluded for various medical reasons. During the screening period a further 12 subjects reconsidered participation so that 42 subjects entered the study.

\section{STUDY DESIGN}

We obtained a 24 hour ambulatory recording of each patient's blood pressure at least four weeks after they had stopped antihypertensive treatment, and then we assigned them to either the relaxation or the control group by simple blocked randomisation (sealed envelopes). They were encouraged not to change their diet or physical activity. Urinary 24 hour sodium excretion and serum cholesterol concentration were determined at the beginning and end of the study. After one year of follow up with monthly control visits
Correspondence to:

Br.Med f 1990;300:1368-72 
a second 24 hour recording of blood pressure was obtained.

\section{RELAXATION PROCEDURES}

We used the approach for relaxation described by Patel et al. ${ }^{61011}$ Briefly, a relaxation therapist trained patients for one hour a week for eight weeks in hatha yoga breathing and posture exercises, ${ }^{12}$ Jacobson's method of progressive relaxation (straining and subsequent relaxation of the major muscle groups), ${ }^{13}$ and exercises derived from the autogenic training method by Schultz and Luthe. ${ }^{14}$ Subjects were also taught how to elicit the relaxation response by using the simple meditative technique proposed by Benson. ${ }^{15}$ Subjects were instructed individually at the first session and thereafter in groups of not more than three. They were asked and encouraged to exercise twice a day at home for 15 minutes with the aid of cassette tapes and a tutorial. As in the programme of Patel et al the concept of stress management and reappraisal and the importance of integrating relaxation into everyday life were extensively discussed. During the follow up period subjects were seen individually at monthly intervals by the same therapist.

\section{CONTROL PROCEDURES}

To ensure that the subjects in the two groups would have a similar expectation that their blood pressure would fall those in the control group were told that the study was comparing the effects of two different approaches of relaxation therapy - passive and active. A research nurse without any training in behavioural procedures conducted all sessions in passive relaxation. The presumed role of stress in hypertension was explained and subjects were asked to relax in a comfortable chair at home twice daily for 15 minutes without any specific instructions. They were not taught any coping strategies or given cassette tapes. At the monthly follow up visits subjects were seen individually by the same nurse, who inquired about stressful periods and the influence of the daily rest on their general wellbeing. Care was taken that subjects from the different groups did not meet or acquire extracurricular relaxation skills.

By using non-specific counselling we aimed to control for important confounding variables such as the frequency of visits, the amount of contact with the therapist, time spent exercising at home, and in general a change in lifestyle.

\section{SPHYGMOMANOMETRY}

Each patient's blood pressure was measured monthly in triplicate with a random zero sphygmomanometer and an appropriately sized cuff, ${ }^{16}$ by GAvM during screening and follow up and by the therapist or research nurse during the training period. Diastolic pressure was read at phase $\mathrm{V}$ of the Korotkoff sounds. To compare the initial measurement with that taken after one year of follow up we took the average of the nine readings obtained at three visits (before, during, and after the ambulatory recordings).

MONITORING INTRA-ARTERIAL AMBULATORY BLOOD PRESSURE

We recorded ambulatory blood pressure for 24 hours using the Oxford technique for intra-arterial monitoring. ${ }^{87-19}$ After cannulation of the brachial artery at 0930 subjects left the hospital to resume their normal daily routine. They were requested to record all activities, such as changes in mental or physical activity and times of going to bed and waking, in a diary and on tape with a push button marker. At 1730 they returned to the hospital for recalibration of the transducer. All subjects slept at home.

The diaries were used to produce an hourly activity list that was discussed with the subject before the second recording to try to ensure that his or her activity pattern was similar to that during the first recording. The 24 hour record was digitised by computer and edited to reject damped waves or artefacts.

The systolic, mean, and diastolic values of each beat were calculated to produce hourly averages with standard deviations of the frequency histograms. These standard deviations were considered as a measure of short term variability in blood pressure. ${ }^{20}$ Blood pressure was averaged for three periods: 1000 to 1800 (daytime); 1800 until bedtime (evening); and for all hours at night (night time). The standard deviation of these averages for each subject was taken as a measure of long term variability in blood pressure..$^{20}$

\section{STATISTICS}

The Statgraphics package (STSC, Rockville, Maryland, United States) was used to compare blood pressure within and between groups with two tailed paired or unpaired $t$ tests and to calculate $95 \%$ confidence intervals. Measures of variability were compared non-parametrically (Wilcoxon signed rank or Mann-Whitney U test). Means and their standard deviations are reported throughout.

\section{Results}

Twenty three of the 42 subjects were allocated to the relaxation group and 19 to the control group. Three men withdrew from the relaxation group during the training period because of time constraints or disappointment with the exercises. Nine months after randomisation one subject moved out of the area, and in one subject the 24 hour recording after one year was of poor technical quality. Two women were withdrawn from the control group, one because of aspecific chest pain and the other because her diastolic blood pressure at the monthly visits increased above $115 \mathrm{~mm} \mathrm{Hg}$.

The study group thus comprised 18 subjects in the relaxation group ( 10 men and eight women, mean age 40 (range 24-56)) and 17 subjects in the control group (eight men and nine women, mean age 43 (range 30-60)). Eleven subjects in the relaxation group and six in the control group were receiving antihypertensive drugs on entry to the study; these were stopped at the first visit, on average six and seven weeks respectively before the initial ambulatory recording. Throughout the follow up period reported compliance with the study programme was excellent in both groups. Initial weight, cholesterol concentration, and 24 hour urinary sodium excretion in the two groups were comparable and did not change (table I).

\section{SPHYGMOMANOMETRY}

Systolic and diastolic blood pressures measured by sphygmomanometry were identical in the two groups and decreased slightly to the same extent during the study. For diastolic pressure these reductions were significant, but the upper limit of the $95 \%$ confidence interval was close to zero (mean change $2.4 \mathrm{~mm} \mathrm{Hg}$ $(95 \%$ confidence interval $-4 \cdot 8$ to $-0 \cdot 1) ; t=2 \cdot 2, \mathrm{df}=$ $17, \mathrm{p}<0.05)$ and $3.1 \mathrm{~mm} \mathrm{Hg}(-5.6$ to 0.6$), t=2.63$, $\mathrm{p}<0.02$ respectively) (table $\mathrm{I}$ ).

Figure 1 shows the blood pressure at each visit during the year of the study. Blood pressure fell between the first screening visit and the first training visit, but no further decrease was seen.

\section{HOUR AMBULATORY BLOOD PRESSURE}

Figure 2 shows the course of the first and second 24 hour blood pressure recordings plotted as hourly means. The curves were identical during the day and evening and on average $5 \mathrm{~mm} \mathrm{Hg}$ higher after one year 


\begin{tabular}{|c|c|c|c|c|c|c|c|c|}
\hline & \multicolumn{4}{|c|}{ Relaxation group $(n=18)$} & \multicolumn{4}{|c|}{ Control group $(\mathrm{n}=17)$} \\
\hline & Initial value & $\begin{array}{l}\text { Change at } \\
\text { follow up }\end{array}$ & $\begin{array}{c}95 \% \text { Confidence } \\
\text { interval }\end{array}$ & $\mathrm{p}$ Value & Initial value & $\begin{array}{l}\text { Change at } \\
\text { follow up }\end{array}$ & $\begin{array}{c}95 \% \text { Confidence } \\
\text { interval }\end{array}$ & $\mathrm{p}$ Value \\
\hline \multicolumn{9}{|l|}{ Blood pressure $(\mathrm{mm} \mathrm{Hg})$ : } \\
\hline Systolic & $153 \cdot 2(14 \cdot 0)$ & $-2 \cdot 2(7 \cdot 7)$ & -6.0 to 1.7 & NS & $156 \cdot 2(12 \cdot 1)$ & $-2 \cdot 5(6 \cdot 8)$ & $-6 \cdot 0$ to $1 \cdot 0$ & NS \\
\hline Diastolic & $100 \cdot 7(3 \cdot 8)$ & $-2 \cdot 4(4 \cdot 7)$ & $-4 \cdot 8$ to $0 \cdot 1$ & $<0.05$ & $98 \cdot 9(5 \cdot 8)$ & $-3 \cdot 1(4 \cdot 9)$ & $-5 \cdot 6$ to $0 \cdot 6$ & $<0.02$ \\
\hline Weight $(\mathrm{kg})$ & $72 \cdot 5(12 \cdot 1)$ & $0 \cdot 0(2 \cdot 4)$ & $-1 \cdot 1$ to $1 \cdot 3$ & NS & $74 \cdot 0(12 \cdot 4)$ & $-1 \cdot 5(4 \cdot 0)$ & $-3 \cdot 6$ to 0.5 & NS \\
\hline Cholesterol $(\mathrm{mmol} / \mathrm{l})$ & $5 \cdot 9(0 \cdot 7)$ & $0 \cdot 2(0 \cdot 7)$ & $-0 \cdot 1$ to $0 \cdot 6$ & NS & $6 \cdot 2(0 \cdot 8)$ & $0 \cdot 2(0 \cdot 8)$ & -0.2 to 0.5 & NS \\
\hline 24 Hour sodium excretion $(\mathrm{mmol} / \mathrm{l})$ & 1) $137 \cdot 7(33 \cdot 6)$ & $2 \cdot 1(56 \cdot 9)$ & $-28 \cdot 3$ to $32 \cdot 4$ & NS & $141 \cdot 2(62 \cdot 6)$ & $3 \cdot 2(48 \cdot 7)$ & $-21 \cdot 9$ to $28 \cdot 2$ & NS \\
\hline
\end{tabular}

TABLE II -Subjects' intra-arterial ambulatory blood pressure at start of trial and at one year follow up. Values are means (SD)

\begin{tabular}{|c|c|c|c|c|c|c|}
\hline & Blood pressure $(\mathrm{mm} \mathrm{Hg})$ & Initial value & Value at follow up & Difference & $95 \%$ Confidence interval & p Value \\
\hline Day & $\left\{\begin{array}{l}\text { Systolic } \\
\text { Diastolic } \\
\text { Mean arterial }\end{array}\right.$ & $\begin{array}{r}158 \cdot 1(13 \cdot 9) \\
98 \cdot 2(10 \cdot 4) \\
121 \cdot 2(10 \cdot 8)\end{array}$ & $\begin{array}{r}\text { Relaxation group } \\
154 \cdot 8(14 \cdot 3) \\
97 \cdot 1(9 \cdot 6) \\
119 \cdot 7(11 \cdot 2)\end{array}$ & $\begin{array}{l}-3.3(10 \cdot 7) \\
-1.0(10.0) \\
-1.5(9.9)\end{array}$ & $\begin{array}{l}-8.6 \text { to } 2 \cdot 0 \\
-6.0 \text { to } 3 \cdot 9 \\
-6.5 \text { to } 3 \cdot 4\end{array}$ & $\begin{array}{l}\text { NS } \\
\text { NS } \\
\text { NS }\end{array}$ \\
\hline Evening & $\begin{array}{l}\text { Systolic } \\
\text { Diastolic } \\
\text { Mean arterial }\end{array}$ & $\begin{array}{c}151 \cdot 3(17 \cdot 6) \\
93 \cdot 0(8 \cdot 8) \\
116 \cdot 1(12 \cdot 1)\end{array}$ & $\begin{array}{c}148 \cdot 6(14 \cdot 7) \\
92 \cdot 8(7 \cdot 7) \\
115 \cdot 1(10 \cdot 3)\end{array}$ & $\begin{array}{l}-2 \cdot 7(8.9) \\
-0 \cdot 2(6 \cdot 1) \\
-1 \cdot 0(6 \cdot 9)\end{array}$ & $\begin{array}{l}-7 \cdot 1 \text { to } 1 \cdot 7 \\
-3 \cdot 2 \text { to } 2 \cdot 8 \\
-4 \cdot 4 \text { to } 2 \cdot 5\end{array}$ & $\begin{array}{l}\text { NS } \\
\text { NS } \\
\text { NS }\end{array}$ \\
\hline Night & $\begin{array}{l}\text { Systolic } \\
\text { Diastolic } \\
\text { Mean arterial }\end{array}$ & $\begin{array}{r}115 \cdot 4(16 \cdot 6) \\
69 \cdot 9(10 \cdot 0) \\
88.9(12 \cdot 6)\end{array}$ & $\begin{array}{c}121 \cdot 0(13 \cdot 4) \\
75 \cdot 2(7 \cdot 3) \\
94 \cdot 4(9 \cdot 5) \\
\text { Control group }\end{array}$ & $\begin{array}{l}5 \cdot 6(8 \cdot 6) \\
5 \cdot 3(6 \cdot 3) \\
5 \cdot 5(7 \cdot 1)\end{array}$ & $\begin{array}{l}1.4 \text { to } 9.9 \\
2.1 \text { to } 8.4 \\
1.9 \text { to } 9.0\end{array}$ & $\begin{array}{l}<0 \cdot 02 \\
<0 \cdot 01 \\
<0 \cdot 01\end{array}$ \\
\hline Day & $\begin{array}{l}\text { Systolic } \\
\text { Diastolic } \\
\text { Mean arterial }\end{array}$ & $\begin{array}{c}161 \cdot 5(14 \cdot 4) \\
96 \cdot 5(8 \cdot 8) \\
122 \cdot 2(10 \cdot 5)\end{array}$ & $\begin{array}{r}162 \cdot 5(19 \cdot 6) \\
96 \cdot 1(11 \cdot 8) \\
121 \cdot 9(14 \cdot 2)\end{array}$ & $\begin{array}{c}1 \cdot 0(17 \cdot 6) \\
-0.4(9 \cdot 6) \\
-0.3(11 \cdot 9)\end{array}$ & $\begin{array}{l}-8 \cdot 1 \text { to } 10 \cdot 0 \\
-5 \cdot 3 \text { to } 4 \cdot 6 \\
-6 \cdot 4 \text { to } 5 \cdot 8\end{array}$ & $\begin{array}{l}\text { NS } \\
\text { NS } \\
\text { NS }\end{array}$ \\
\hline Evening & $\begin{array}{l}\text { Svstolic } \\
\text { Diastolic } \\
\text { Mean arterial }\end{array}$ & $\begin{array}{c}154 \cdot 8(14 \cdot 6) \\
91 \cdot 9(8 \cdot 7) \\
117 \cdot 0(10 \cdot 0)\end{array}$ & $\begin{array}{r}154 \cdot 6(19 \cdot 4) \\
92 \cdot 0(10 \cdot 1) \\
117 \cdot 2(13 \cdot 2)\end{array}$ & $\begin{array}{c}-0 \cdot 2(16 \cdot 1) \\
0 \cdot 1(7 \cdot 5) \\
0 \cdot 2(10 \cdot 5)\end{array}$ & $\begin{array}{l}-8 \cdot 3 \text { to } 8 \cdot 2 \\
-3 \cdot 7 \text { to } 3 \cdot 9 \\
-5 \cdot 3 \text { to } 5 \cdot 6\end{array}$ & $\begin{array}{l}\text { NS } \\
\text { NS } \\
\text { NS }\end{array}$ \\
\hline Night & $\begin{array}{l}\text { Systolic } \\
\text { Diastolic } \\
\text { Mean arterial }\end{array}$ & $\begin{array}{r}116 \cdot 4(15 \cdot 9) \\
68 \cdot 0(10 \cdot 7) \\
88 \cdot 2(12 \cdot 4)\end{array}$ & $\begin{array}{c}122 \cdot 1(15 \cdot 9) \\
73 \cdot 0(9 \cdot 0) \\
93 \cdot 4(11 \cdot 5)\end{array}$ & $\begin{array}{l}5 \cdot 7(11 \cdot 4) \\
5 \cdot 0(7 \cdot 7) \\
5 \cdot 2(9 \cdot 0)\end{array}$ & $\begin{array}{c}-0.1 \text { to } 11.5 \\
1.0 \text { to } 9.9 \\
0.5 \text { to } 9.8\end{array}$ & $\begin{array}{l}<0.05 \\
<0 \cdot 02 \\
<0 \cdot 05\end{array}$ \\
\hline
\end{tabular}

TABLE III - Short term and long term variability in mean arterial blood pressure at start of study and at one year follow up. Values are averaged standard deviations $(\mathrm{mm} \mathrm{Hg})^{\star}$

\begin{tabular}{|c|c|c|c|c|c|c|c|c|}
\hline & \multicolumn{4}{|c|}{ Relaxation group $(\mathbf{n}=18)$} & \multicolumn{4}{|c|}{ Control group $(n=17)$} \\
\hline & \multicolumn{2}{|c|}{ Short term } & \multicolumn{2}{|c|}{ Long term } & \multicolumn{2}{|c|}{ Short term } & \multicolumn{2}{|c|}{ Long term } \\
\hline & Initial value & Value at follow up & Initial value & Value at follow up & Initial value & Value at follow up & Initial value & Value at follow up \\
\hline Day & $9 \cdot 8$ & $9 \cdot 7$ & $7 \cdot 1$ & $5 \cdot 4$ & $9 \cdot 8$ & $9 \cdot 7$ & $7 \cdot 4$ & $5 \cdot 3$ \\
\hline Evening & $9 \cdot 1$ & $9 \cdot 1$ & $7 \cdot 7$ & $7 \cdot 8$ & $9 \cdot 4$ & $9 \cdot 5$ & $9 \cdot 2$ & $8 \cdot 8$ \\
\hline Night & $6 \cdot 7$ & 6.9 & $6 \cdot 4$ & 4.7 & $7 \cdot 2$ & $7 \cdot 3$ & $6 \cdot 7$ & $6 \cdot 6$ \\
\hline
\end{tabular}

*All comparisons within-groups (Wilcoxon signed rank test) and between groups (Mann-Whitney U test) were not significant.

in both groups for most hours at night. These curves showed the usual diurnal pattern found by intraarterial monitoring, with a difference in pressure between being awake and asleep of roughly $25 \%$.

Group means, changes, and $95 \%$ confidence intervals were calculated for averaged daytime, evening, and night time ambulatory blood pressure during the initial recording and after one year (table II). Mean changes for daytime and evening periods and all measures of variability in the two groups were very small or zero (table III). Small treatment effects, however, could not be ruled out with certainty, as illustrated by the confidence intervals.

After one year the mean arterial pressure during daytime had fallen by $10 \%$ in two subjects in the relaxation group and one in the control group and had risen by $10 \%$ in the same number of subjects in each group. No relation was found between the $5 \mathrm{~mm} \mathrm{Hg}$ increase in night time pressures after one year, and differences in the times of going to bed and waking up or previous use of antihypertensive drugs.

\section{Discussion}

We found that the effects on 24 hour intra-arterial ambulatory blood pressure of one year's daily muscle relaxation and yoga exercises were identical with those observed in a control group that did not take exercise and of questionable biological importance. ${ }^{21}$ No relevant changes in blood pressure or its variability were observed either in the daytime or during the evening or the night, when presumably sympathetic activity is reduced. Our findings confirm those of two recent studies in which modest reductions in blood pressures were found in the clinic but not outside it ${ }^{223}$ but are inconsistent with those of several other studies reporting sizable reductions in blood pressure at the clinic. ${ }^{10} 112+28$

Why did we fail to observe a relevant effect in the relaxation group? The problem with behavioural treatments is that several variables that are assumed to be critical for success are difficult to measure ${ }^{2129}-$ for example, the type of therapy and the clinical skills of the therapist. Even more difficult to assess are the patients' characteristics, expectations of the treatment, and interactions with the therapist. These complicated and subjective factors make generalisations from single behavioural studies difficult, regardless of their outcome.

We closely followed the comprehensive "basket" approach of Patel et al, with a battery of procedures aimed at different physiological mechanisms, ${ }^{111}$ "but failed to reproduce their results. Since 1973 they have reported an impressive series of successful studies $^{101125-28}$ and have emphasised the paramount role of the therapist, who clearly is more instrumental in success than the methods used or even the number of hours of training. ${ }^{3}$ Although admitting the importance of the therapist in arousal-reduction treatment, Patel and Marmot recently reported that selected general 
practitioners and nurses who were instructed as therapists for only one weekend achieved relevant reductions in blood pressures..$^{2 \mathrm{X}}$ We are not convinced that other important factors for success, such as compliance or expectation, prevented us from producing a relevant effect with relaxation. The drop out rate $(17 \%)$ was acceptable, and the remaining subjects were highly motivated to complete the study and not take drugs. In general, they reported feeling more relaxed and appreciated the daily relaxation routine.

Our procedures differed in two ways from those used by Patel et al. Firstly, we did not use biofeedback equipment because we wanted the procedures to be widely applicable and cost effective, and also because adding biofeedback to relaxation has not been proved to be more effective than relaxation alone. ${ }^{3031}$ Secondly,

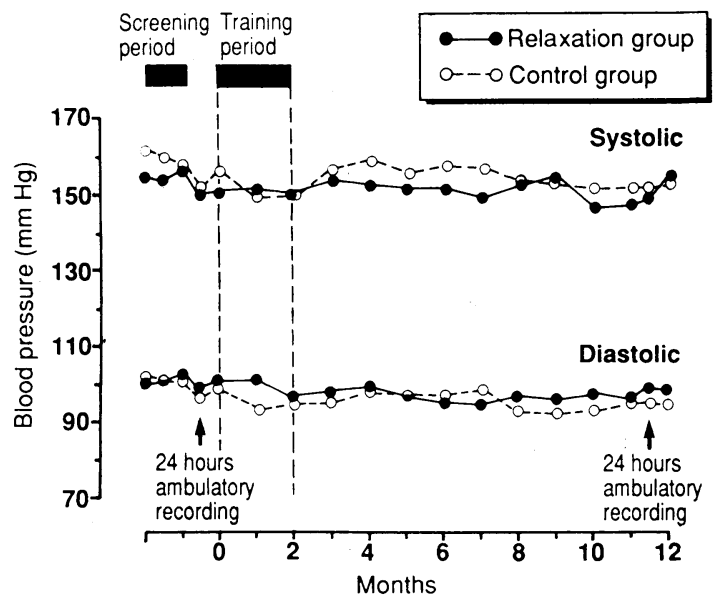

FIG 1-Course of blood pressure measured by sphygmomanometry during one year's follow up

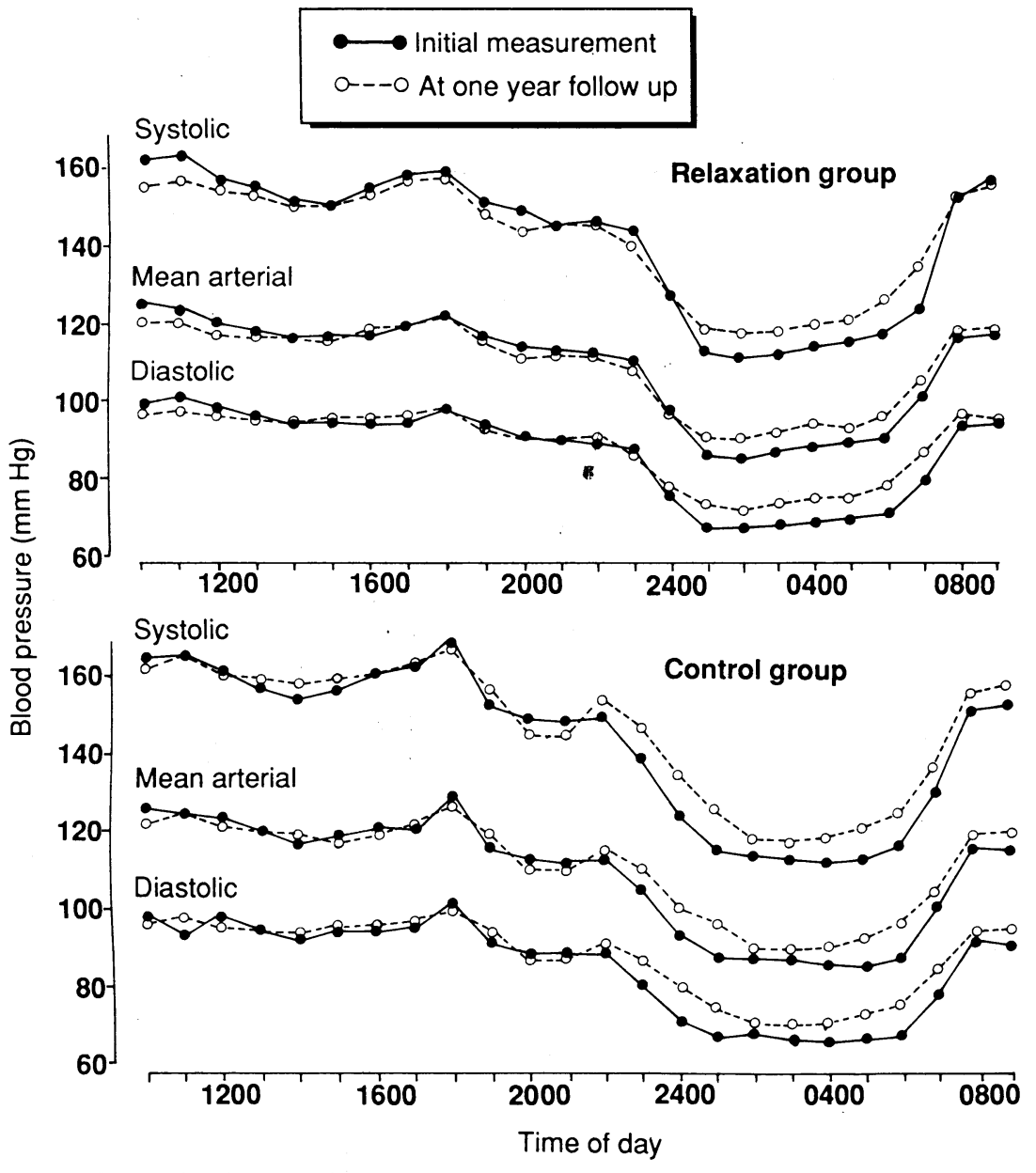

FIG 2-Course of 24 hour ambulatory intra-arterial blood pressure (Oxford system) before and after one year's relaxation therapy (top) and non-specific counselling (bottom). Values plotted are hourly averages and perhaps more importantly, we specifically advised subjects not to change their dietary habits and physical activity as the study was aimed at assessing the specific effects of relaxation training.

The possibility that our fairly small trial yielded false negative results also merits comment. We intended to have sufficient power to detect important differences clinically rather than epidemiologically; but although the averaged intervention effects were negligible, the modest sample size and the somewhat greater than expected variability in blood pressure limited the study's power. The confidence intervals for the effects on ambulatory blood pressure, however, did not in our opinion embrace clinically relevant differences. Thus we found relaxation therapy to be ineffective in achieving sustained and clinically relevant reductions in 24 hour blood pressure, just as ineffective as nonspecific counselling. In so far as treatment effects were observed, these could just as well have been caused by non-specific factors. In combination with other nonpharmacological methods relaxation therapy may be useful for some to enhance wellbeing and compliance but will not in our opinion be more effective-or less ineffective ${ }^{2}$-than support or reassurance in the traditional sense.

We thank the practitioners who referred their patients, Ingrid Schols and Hester de Melker for conducting the relaxation sessions and non-specific counselling, Hans Karemaker and Jacques van der Hofstede for developing software, and Hans Oosting for statistical advice. We also acknowledge the comments by Guido Godaert and Harry Büller. This study was supported by The Netherlands Heart Foundation.

1 Health and Public Policy Committee, American College of Physicians. Biofeedback for hypertension. Ann Intern Med 1985;102:709-15.

2 Subcommittee on Nonpharmacological Therapy of the 1984 Joint National Committee on Detection, Evaluation, and Treatment of High Blood Pressure. Nonpharmacological approaches to the control of high blood pressure. Final report. Hypertension 1986;8:444-67.

Ward MM, Swan GE. Chesney MA. Arousal-reduction treatments for mild hypertension: a meta-analysis of recent studies. In: Julius S, Bassett DR eds. Handbook of hypertension. Vol 9: Behavioural factors in hypertension Amsterdam: Elsevier Science, 1987:285-302.

4 Pickering TG, Harshfield GA, Devereux RB, Laragh JH. What is the role of ambulatory blood pressure monitoring in the management of hypertensive patients? Hypertension 1985:7:171-7

5 Jovce CRB. Placebos and other comparative treatments. In: de Saintonge DC Vere DW, eds. Current problems in clinical trials. Oxford: Blackwell Scientific, 1984:23-8.

6 Patel $\mathrm{C}$ A new dimension on the prevention of coronary heart disease. In: Dembroski TMI, Schmidt TH, Blumchen $\mathrm{G}$, eds. Bioheharioral bases of coronary heart disease. Basle: Karger, 1983:416-38.

7 Brauer AP. Horlick L, Nelson E, Farquhar JW, Agras WS. Relaxation therapy for essential hypertension: a Veterans Administration outpatient study. F Behur. Med 1979:2:21-9.

8 Littler WA, Honour AJ, Sleight P, Stott FD. Continuous recording of direct arterial pressure and electrocardiogram in unrestricted man. Br Med 1972;iii:76-8.

9 Sleight P. Ambulatory blood pressure monitoring. Hypertension 1985;7:163-4

10 Patel C, Marmot MG, Terry DJ. Controlled trial of biofeedback-aided behavioural methods in reducing mild hypertension. Br. Med f 1981;282 2005-8.

11 Patel C, Marmot MG, Terry DJ, Carruthers $M$, Hunt B, Patel $M$. Trial of relaxation in reducing coronary risk: four vear follow up. $\mathrm{Br}$ Med $\mathrm{J}$ 1985:290:1103-6

12 Hitrleman RL. Yoga: the 8 steps to health and peace. London: Hamlyn, 1976.

13 Jacobson $\mathrm{E}$. Variation of blood pressure with skeletal muscle tension and relaxation. Ann Intern Med 1939;1194:212.

14 Schuly JH, Luthe $\mathrm{W}$, Autogenic therapy. I Autogenic methods. New York: Grune and Stratton, 1969

15 Benson H. Systemic hypertension and the relaxation response. $N$ Engl f. Med 1977;296:1152-6

16 Van Montfrans GA, van der Hoeven GMA, Karemaker JM, Wieling W Dunning AJ. Accuracy of auscultatory blood pressure measurement with long cuff. Br.Med $\mathcal{F}$ 1987;295:354-5

17 Bevan AT, Honour AJ, Stott FD. Direct arterial pressure recording in unrestricted man. Clin Sci 1969;39:329-44

18 Millar-Craig MW, Hawes D, Whittington J. New system for recording ambulatory blood pressure in man. Med Biol ling Comput 1978:16:727-31.

19 Mann S, Jones RI, Millar-Craig MW, W'ood C, Gould BA, Raftery EB. The safety of ambulatory intra-arterial pressure monitoring: a clinical audit of 1000 studies. Int 7 Curdiol 1984;5:585-97.

20 Mancia G, Ferrari A. Gregorini L. et al. Blood pressure and heart rate variability in normotensive and hopertensive human beings. Circ $R_{0}$ 1983:53:96-104.

21 Shapiro AP, Schwary GE, Ferguson DCE, Redmond DP, Weiss SM Behavioral methods in the treatment of hypertension. A review of their clinical status. An Intern. Med 1977;86:626-36.

22 Jacob RG, Shapiro AP, Reeves RA, Johnsen AM, McDonald RH, Cohurn C, 

comitant placebo, diuretic and $\beta$-blocker. Arch Intern Med 1986;146:233540.

23 Cottier C, Shapiro K, Julius S. Treatment of mild hypertension with progressive muscle relaxation. Predictive value of indices of sympathetic tone. Arch Intern Med 1984;144:1954-8.

24 Bali LR. Long-term effects of relaxation on blood pressure and anxiety levels of essential hypertensive males: a controlled study. Psychom Med 1979;41 $637-4$

25 Patel C. Yoga and biofeedback in the management of hypertension. Lancet 1973;ii: 1053-5.

26 Patel C. 12-month follow-up of yoga and biofeedback in the management of hypertension. Lancet 1975;i:62-5.
27 Patel C, North WRS. Randomised controlled trial of voga and biofeedback in the management of hypertension. Lancet 1975;ii:93-5.

28 Patel C. Marmot M. Can general practitioners use training in relaxation and

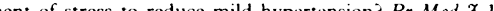
man 1 -4.

29 Patel C, Marmot MG. Stress management, blood pressure and quality of life. 7 Hypertens 1987;5 (suppl 1) S21.

30 Andrews G, MacMahon SW, Austin A, Byrne DG. Hypertension: comparison of drug and non-drug treatments. Br Med J 1984;284:1523-6.

31 Little BC, Hayworth J, Benson P, et al. Treatment of hypertension in pregnancy by relaxation and biofeedback. Lancet 1984;i:865-7.

(Accepted 22 February 1990)

\title{
Sociodemographic and motivational characteristics of parents who volunteer their children for clinical research: a controlled study
}

\author{
S C Harth, Y H Thong
}

\begin{abstract}
Objective-To determine the sociodemographic and motivational characteristics of parents who volunteer their children for clinical research.

Design-A questionnaire was administered to parents who volunteered their children for a randomised, double blind, placebo controlled trial of a drug to treat asthma and to a control group of parents whose children were eligible for the trial but had refused the invitation.
\end{abstract}

Setting-A children's hospital in Australia.

Subjects -68 Parents who had volunteered their children and $\mathbf{4 2}$ who had not; a response rate of $94 \%$ and $70 \%$, respectively.

Main outcome measures-Responses of parents to questionnaire designed to assess their perceptions, attitudes, and health seeking behaviour as well as sociodemographic data.

Results-Volunteering parents were less well educated with only $15 \%(10 / 68)$ of mothers and $16 \%$ $(11 / 68)$ and of fathers having had a tertiary or university education compared with $26 \%$ (11/42) of mothers and $45 \%(19 / 42)$ in the non-volunteering group. Fewer volunteering parents had professional or administrative jobs than did non-volunteering parents (mothers 6\% (4/68); fathers 9\% $(6 / 68) v$ mothers $14 \%(6 / 42)$; fathers $31 \%(13 / 42))$. Volunteering parents had less social support, and they displayed greater health seeking behaviour and consumed more habit forming substances. They were motivated by a desire to help others and to contribute to medical research, but they were also searching for more information and better ways to help their own children.

Conclusion-Parents who volunteer their children for medical research are significantly more socially disadvantaged and emotionally vulnerable.

Department of Child

Health, University of Queensland, Mater Children's Hospital, South Brisbane, Queensland 4101, Australia

SC Harth, RN, senior research assistant

Y H Thong, FRACP, professor of child health

Correspondence to:

Professor Thong.

BrMed F 1990;300:1372-5 and cannot be readily extrapolated to clinical studies. ${ }^{7-11}$

The role of children as research subjects has been the focus of much philosophical inquiry and scholarly debate because of their special vulnerability and inherent inability to provide fully informed consent, but much of this discussion has focused on the types of research permissible in children, the adequacies and inadequacies of informed consent, and the details of legal and regulatory provisions. ${ }^{12-16}$ To our knowledge, no information is available about the profile of parents who volunteer their children for clinical research. Knowledge about the sociodemographic and motivational characteristics of such parents may provide a useful contribution to this ethical discussion. We studied the characteristics of parents who volunteered their children for a trial of a drug for treating asthma. We report on their sociodemographic and motivational characteristics; data on their psychological profiles will be presented on completion of psychometric analysis.

\section{Subjects and methods}

We studied the parents who had volunteered their children for a randomised, double blind, placebo controlled trial of ketotifen, a new drug for asthma that is unlicensed in Australia. To be eligible for the trial the children had to be aged between 1 and 3 years and have had symptoms of coughing and wheezing for the three months before entering the trial and during the one month assessment period before starting the treatment. In addition, none of the children was taking corticosteroids or cromoglycate, and all were responding badly to the bronchodilators salbutamol and theophylline. Altogether, 72 volunteered children satisfied these criteria and the parents of 68 agreed to be interviewed. The comparison group (non-volunteering parents) was recruited from the parents of 60 children who had been invited to allow their children to participate in the trial but who had refused after due consideration. Altogether, 42 children's parents were interviewed, giving a participation rate of $70 \%$. The parents were not paid but were given travel subsidies to enable them to bring their children for regular assessment. The study was approved by the Mater Hospital ethics committee.

A questionnaire consisting of 48 structured and two openended sections, each with two to 16 questions, was designed to assess the perceptions, attitudes, and health seeking behaviour of the volunteering and nonvolunteering parents. Detailed sociodemographic information on both parents of each child was obtained and defined by categories similar to those given in the latest Australian census. "? The parents who had made the main part of the decision to either allow or refuse 